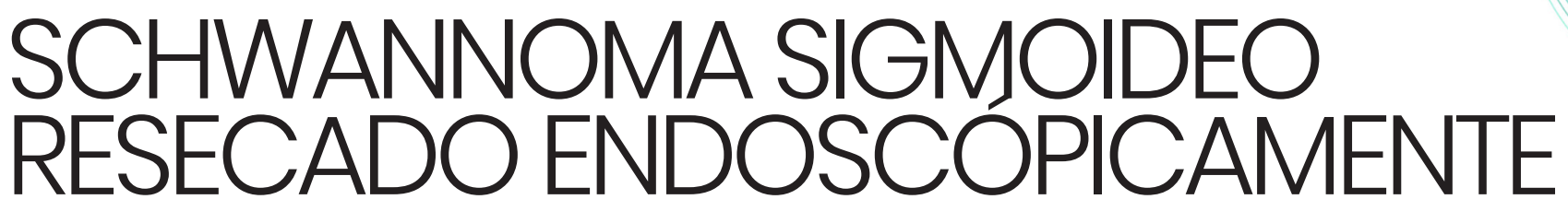

\title{
SIGMOID SCHWANNOMA TREATED BY ENDOSCOPIC RESECTION
}

\section{Carnerero Rodríguez JA', Pérez Luque A², Rivas Rivas M', Iglesias Arrabal $\mathrm{M}^{2}$}

'Hospital de Alta Resolución La Janda. Vejer de la Frontera. Cádiz.

${ }^{2}$ Hospital Universitario Puerta del Mar. Cádiz.

\section{Resumen}

Los schwannomas colorrectales son extremadamente raros y existe poca información sobre el diagnóstico y manejo de esta entidad. Presentamos un nuevo caso de schwannoma sigmoideo y discutimos la forma de presentación clínica, imágenes obtenidas y evolución.

Palabras clave: schwannoma, tumor gastrointestinal, resección endoscópica.

\section{Abstract}

Colorectal schwannomas are extremely rare and little information exists on the diagnosis and management of this entity. We present a new case of a sigmoid colon schwannoma and we discuss the clinical presentation, images obtained and clinical course.

\section{CORRESPONDENCIA}

José Antonio Carnerero Rodríguez

Hospital de Alta Resolución La Janda

11150 Vejer de la Frontera (Cádiz)

carnererojosea38m@gmail.com

Fecha de envío: 26/12/2020

Fecha de aceptación: 27/01/2020
Keywords: schwannoma, gastrointestinal tumor, endoscopic resection.

\section{Introducción}

Los schwannomas son tumores de la vaina del nervio periférico que se originan a partir de las células de Schwann ${ }^{1,2}$. Su desarrollo en el tracto digestivo es muy infrecuente, siendo excepcional la presentación colorrectal ${ }^{1,2}$.

\section{Caso Clínico}

Mujer de 56 años sin antecedentes relevantes. Se realiza colonoscopia por alteración del ritmo intestinal, identificando en sigma, una lesión polipoidea sésil de aspecto submucoso (Figura1). La lesión es blanda, móvil y presenta una elevación adecuada, por lo que se lleva a cabo su resección con asa de diatermia y se tatúa con tinta china. La anatomía patológica es informada como schwannoma sin datos de malignidad (Figuras 2 y 3 ). La paciente se encuentra asintomática con posteriores revisiones endoscópicas normales. 


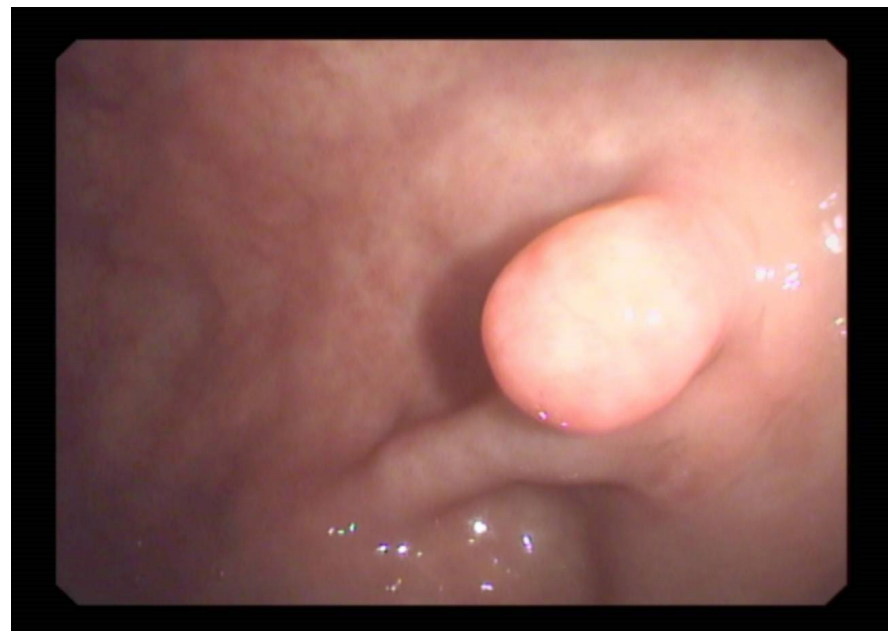

\section{Figura 1}

Colonoscopia. Lesión polipoidea sésil de 7 milímetros de diámetro y aspecto submucoso, localizada en colon sigmoide.

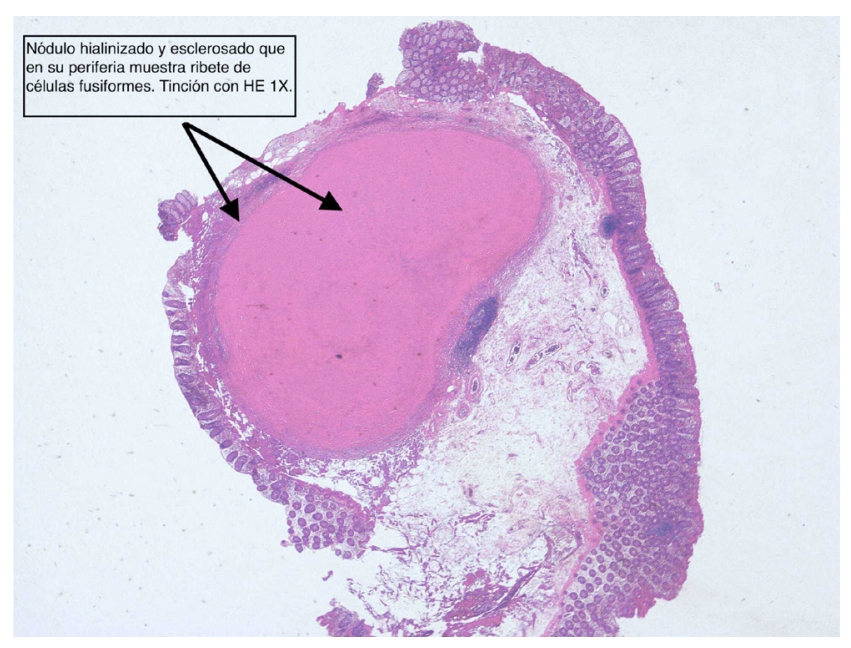

Figura 2

Anatomía patológica. Existencia en submucosa de un nódulo hialinizado y esclerosado, con presencia en su periferia de un ribete de células fusiformes sin atipia.

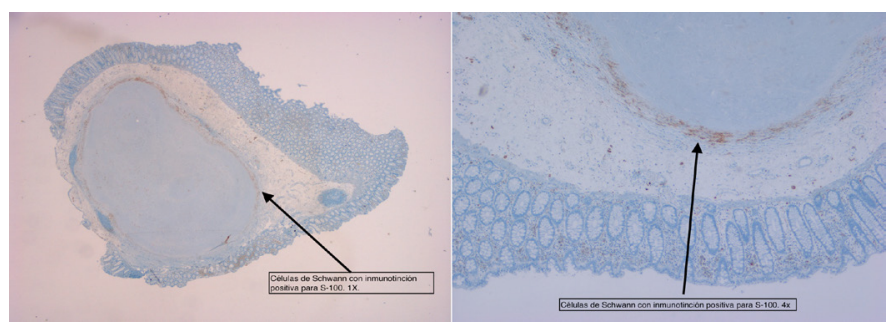

Figura 3

Anatomía Patológica. Células de Schwann con expresión de inmunotición positiva para la proteína S-100.

\section{Discusión}

Los schwannomas representan únicamente el 0,4\%$1 \%$ de los tumores submucosos gastrointestinales ${ }^{2}$. Se localizan principalmente en estómago e intestino delgado, existiendo tan sólo 29 casos descritos en colon sigmoideo ${ }^{1,3}$. Los schwannomas colorrectales se identifican en endoscopia como lesiones submucosas raramente ulceradas, siendo en ocasiones indistinguibles con pólipos de aspecto benigno ${ }^{1-3}$. Pueden ser causa de dolor abdominal, hemorragia digestiva, tenesmo rectal, alteración del tránsito, invaginación y obstrucción intestinal; si bien muchos de ellos se presentan de forma asintomática en colonoscopias de cribado ${ }^{1-3}$. El diagnóstico definitivo se obtiene mediante inmunohistoquímica, siendo las biopsias a menudo insuficientes al asentar el tumor en la capa submucosa ${ }^{1-3}$. Suelen ser benignos, de crecimiento lento y con bajo potencial de degeneración ${ }^{1-3}$. El tratamiento consiste en eliminar la lesión con márgenes de resección negativos, sin disponer de una pauta establecida para su seguimiento ${ }^{1-3}$.

\section{Bibliografía}

1. Bohlok A, El Khoury M, Bormans A, Galdon MG, Vouche M, El Nakadi I et al. Schwannoma of the colon and rectum: a systematic literature review. World J Surg Oncol 2018;16:125.

2. Leonard A, McCarthy LP, Pastor DM. When a polyp is not a polyp: incidental finding of a sigmoid schwannoma at first colonoscopic screening. BMJ Case Rep 2018;2018.

3. Kim G, Kim SI, Lee KY. Case Report: Schwannoma of the sigmoid colon: a case report of a rare colonic neoplasm and review of literature. F1000Res 2019;8:652. 